Research, Society and Development, v. 9, n. 11, e1239119616, 2020

(CC BY 4.0) | ISSN 2525-3409 | DOI: http://dx.doi.org/10.33448/rsd-v9i11.9616

\title{
Sistemas de drenagem urbana e o saneamento: uma análise cienciométrica
}

Urban drainage systems and sanitation: a scientometric analysis

Sistemas de drenaje y saneamiento urbano: un análisis cienciométrico

Recebido: 24/10/2020 | Revisado: 02/11/2020 | Aceito: 03/11/2020 | Publicado: 06/11/2020

Juni Cordeiro

ORCID: https://orcid.org/0000-0001-9371-8385

Universidade Federal de Minas Gerais, Brasil

E-mail: juni.scordeiro@gmail.com

Fábio Henrique Silva

ORCID: https://orcid.org/0000-0003-3503-3761

Universidade Federal de Minas Gerais, Brasil

E-mail: fahenufmg@yahoo.com.br

Felipe Angelo Neves Campera

ORCID: https://orcid.org/0000-0002-9335-5753

Universidade Federal de Minas Gerais, Brasil

E-mail: felipecamperra@ hotmail.com

Flávio Costa

ORCID: https://orcid.org/0000-0002-5039-7064

Universidade Federal de Minas Gerais, Brasil

E-mail: flavio.costa86@yahoo.com.br

\section{Resumo}

Sob a perspectiva da drenagem pluvial, a urbanização é comumente acompanhada pelo rápido aumento de áreas impermeáveis, resultando em mudanças nas características hidrológicas e hidráulicas de uma bacia hidrográfica. Dentre os principais efeitos dessas alterações podem ser citados o aumento da velocidade de escoamento, a elevação dos danos decorrentes de inundações e a possibilidade de poluição dos corpos hídricos pelo carreamento de substâncias. Assim, este trabalho visou analisar a evolução espaço-temporal dos trabalhos científicos publicados e indexados no banco de dados Web of Science quanto a relação entre a drenagem urbana e o saneamento. Foi realizada uma pesquisa cienciométrica que resultou em uma amostra de 34 artigos, analisados por meio da estatística descritiva e análise de conteúdo. Os resultados obtidos indicam um aumento do número de artigos publicados entre 1994 e 2019, 
sendo que o Brasil corresponde ao país com o maior número de publicações $(n=14)$. Com relação às áreas do conhecimento, notou-se que aquelas com maior número de artigos correspondem aos Recursos hídricos (18\%), Ciências ambientais e ecologia (17\%) e Engenharia (12\%). As palavras-chave mais citadas nos artigos foram "sustentabilidade", "drenagem urbana", "gestão", "sistemas", "saneamento", “água", "cidades", "mudanças climáticas", "saúde" e "poluição". Destaca-se a importância de pesquisas multidisciplinares envolvendo novas abordagens de gestão de águas pluviais buscando a construção de cidades mais sustentáveis.

Palavras-chave: Cidades sustentáveis; Escoamento superficial; Inundação; Poluição; Urbanização.

\section{Abstract}

From the perspective of rain drainage, urbanization is commonly accompanied by the rapid increase in impermeable areas, resulting in changes in the hydrological and hydraulic characteristics of a watershed. Among the main effects of these changes can be mentioned the increase in the flow speed, the increase of the damages resulting from floods and the possibility of pollution of the water bodies by the carrying of substances. Thus, this study aimed to analyze the spatio-temporal evolution of scientific works published and indexed in the Web of Science database regarding the relationship between urban drainage and sanitation. A scientometric survey was conducted that resulted in a sample of 34 articles, analyzed using descriptive statistics and content analysis. The results obtained indicate an increase in the number of articles published between 1994 and 2019, with Brazil corresponding to the country with the largest number of publications $(n=14)$. Regarding the areas of knowledge, it was noted that those with the largest number of articles correspond to Water Resources (18\%), Environmental Sciences and Ecology (17\%) and Engineering (12\%). The keywords most cited in the articles were "sustainability", "urban drainage", "management", “systems", “sanitation", “water", “cities", “climate change”, "health" and "pollution". It highlights the importance of multidisciplinary research involving new approaches to rainwater management seeking to build more sustainable cities.

Keywords: Sustainable cities; Surface runoff; Flooding; Pollution; Urbanization.

\section{Resumen}

Desde la perspectiva del drenaje pluvial, la urbanización suele ir acompañada de un rápido aumento de áreas impermeables, lo que resulta en cambios en las características hidrológicas 
e hidráulicas de una cuenca. Entre los principales efectos de estos cambios se pueden mencionar el aumento de la velocidad del flujo, el aumento de los daños por inundaciones y la posibilidad de contaminación de los cuerpos de agua por el transporte de sustancias. Así, este estudio tuvo como objetivo analizar la evolución espaciotemporal de los trabajos científicos publicados e indexados en la base de datos Web of Science sobre la relación entre drenaje urbano y saneamiento. Se realizó una encuesta cienciometría que resultó en una muestra de 34 artículos, analizados mediante estadística descriptiva y análisis de contenido. Los resultados obtenidos indican un aumento en el número de artículos publicados entre 1994 y 2019, correspondiendo Brasil al país con mayor número de publicaciones $(\mathrm{n}=14)$. En cuanto a las áreas de conocimiento, se observó que las que tienen mayor número de artículos corresponden a Recursos Hídricos (18\%), Ciencias Ambientales y Ecología (17\%) e Ingeniería (12\%). Las palabras clave más citadas en los artículos fueron "sostenibilidad", "drenaje urbano", "gestión”, "sistemas", “saneamiento", "agua", "ciudades", “cambio climático", "salud” y “contaminación”. Destaca la importancia de la investigación multidisciplinaria que involucre nuevos enfoques para la gestión del agua de lluvia que buscan construir ciudades más sostenibles.

Palabras clave: Ciudades sostenibles; Escorrentía superficial; Inundación; Contaminación; Urbanización.

\section{Introdução}

As primeiras vilas surgiram junto aos cursos de água porque a disponibilidade desse recurso favorecia o consumo e higiene humanos, além do desenvolvimento da agricultura de subsistência. Contudo, a proximidade entre as cidades e os cursos hídricos resultava em adversidades relacionadas aos excedentes de água, tal como as inundações (Baptista \& Coelho, 2016).

O desenvolvimento das primeiras obras relacionadas à Engenharia Hidráulica possibilitou a condução de água aos locais onde esse recurso era desejado, permitindo a ocupação de diferentes espaços. Entretanto, a intensificação dessa ocupação a partir do século XIX não foi acompanhada por uma infraestrutura adequada de controle das águas nas cidades, relacionadas tanto aos corpos hídricos naturais, como as águas de origem pluvial e as águas servidas (Baptista et al., 2011).

Quando considerados os impactos da urbanização associados à drenagem pluvial, observa-se a alteração do ciclo hidrológico natural da bacia hidrográfica, seja pela redução de 
infiltração (impermeabilização do solo), da interceptação e evapotranspiração (diminuição da cobertura vegetal), reduzindo o tempo de concentração e elevação da vazão máxima de escoamento superficial no exutório.

O hidrograma da bacia também é alterado pela modificação nos leitos dos rios, causando aumento da velocidade de escoamento, mudança da localização das áreas de inundação para jusante e elevação dos danos decorrentes de inundações oriundas de eventos de chuva com o mesmo tempo de retorno. Além disso, o sistema de drenagem pluvial existente se torna subdimensionado, como resultado das modificações das condições nas quais o projeto foi concebido (Butler \& Davies, 2004).

Esses problemas podem ser agravados em função do tipo de sistema de coleta de esgotos e de drenagem pluvial utilizados nas cidades. Nos sistemas separadores absolutos há utilização de tubulações distintas nas redes de esgotamento sanitário e drenagem de águas pluviais, com a intenção de dividir $100 \%$ das vazões oriundas dessas fontes. Já nos sistemas combinados (unitários) há a utilização do mesmo conduto para ambas as contribuições. Os sistemas híbridos (mistos) são aqueles em que há a combinação dessas duas concepções.

Apesar do sistema separador absoluto corresponder à solução considerada ideal por especialistas com relação ao saneamento básico, seu sucesso depende de fiscalização efetiva e controle eficiente para se evitar que ligações clandestinas direcionem águas pluviais, principalmente aquelas provenientes de telhados e pátios, em redes coletoras de esgotos; e águas residuárias domésticas em tubulações e galerias de chuva.

Dessa forma, muitos sistemas planejados para funcionarem como sistema separador terminam funcionando como um sistema misto. Destaca-se ainda que, nesse sistema verificase o aumento da carga poluidora no início da contribuição das águas pluviais (Machado et al., 2013), uma vez que essas águas, ao escoarem pelo solo e em superfícies impermeáveis, podem carrear detritos, sedimentos, compostos químicos e outros poluentes (Davis \& Masten, 2016).

A gestão de águas pluviais não apresentou praticamente nenhuma solução dessas questões até meados da década de 1990 (Gimenez-Maranges et al., 2020), quando foram incorporadas práticas visando melhores resultados ambientais, econômicos, sociais e culturais (Elliott \& Trowsdale, 2007). De modo geral, essas técnicas privilegiam a detenção e infiltração de água, bem como redução de sua velocidade, tais como a utilização de pavimentos porosos, bacias e reservatórios de detenção, tratamento de fundos de vale e uso de áreas não-edificantes (Baptista et al., 2011).

Ainda neste sentido, Mitchell (2006) ressalta que, para um planejamento urbano 
adequado, deve-se buscar a adoção de uma abordagem integrada para a gestão de sistemas de água urbanos, abrangendo o abastecimento de água, drenagem e saneamento como componentes de um sistema físico integrado.

Assim, este trabalho objetiva avaliar a evolução espaço-temporal dos trabalhos científicos publicados e indexados no banco de dados Web of Science relacionados à drenagem urbana e ao saneamento. Buscou-se ainda identificar as principais áreas do conhecimento relacionadas às publicações e as palavras-chave mais citadas nesses artigos, além de verificar o conteúdo dos três artigos mais citados.

\section{Metodologia}

Nessa pesquisa utilizou-se a ciênciometria, que corresponde ao estudo dos aspectos quantitativos da ciência como uma atividade econômica ou disciplina, incluindo a publicação de pesquisas (Macias-Chapula, 1998). De modo geral, os dados cienciométricos são utilizados para o delineamento do perfil dos campos científicos, incluindo a análise da posição dos principais atores envolvidos e as representações associadas a cada um dos ramos do conhecimento (Vanti, 2002).

Dentre os resultados recentes de pesquisas envolvendo a ciênciometria em diferentes temáticas podem ser destacados aqueles obtidos por Guimarães et al. (2018), Rodrigues et al. (2018), Santos et al. (2018) e Ferreira et al. (2019).

Os dados analisados nesse trabalho foram obtidos no banco de dados Web of Science por meio de pesquisa realizada no mês de setembro de 2020, utilizando as palavras-chave, em inglês, "urban drainage" (drenagem urbana) AND "sanitation" (saneamento).

Foram encontrados 34 artigos, publicados entre os anos de 1994 e 2019, que compõem a amostra desta pesquisa. As informações analisadas correspondem à evolução temporal do número de artigos publicados, aos países de origem e às áreas de conhecimentos associadas à essas publicações e às palavras-chave mais citadas. Buscou-se ainda verificar o conteúdo dos 3 trabalhos mais citados, considerando as informações disponíveis no banco de dados Web of Science.

Os dados obtidos foram tratados por meio da estatística descritiva e análise de conteúdo. A primeira foi utilizada para quantificar as informações publicadas sobre o tema “drenagem urbana e saneamento" entre os anos de 1994 e 2019. A análise de conteúdo foi utilizada com o intuito de descrever as informações vinculadas à essa temática. 


\section{Resultados e Discussão}

Considerando a evolução espaço-temporal dos artigos publicados sobre a drenagem urbana e saneamento é possível notar na Figura 1 um crescimento no número de trabalhos científicos a partir de 2017. Faz-se importante salientar que o ano de início da busca de artigos foi determinada pelas palavras-chaves utilizadas na pesquisa e pela disponibilidade de trabalhos no banco de dados Web of Science.

Figura 1 - Evolução dos artigos publicados sobre a drenagem urbana e saneamento entre 1994 e 2019.

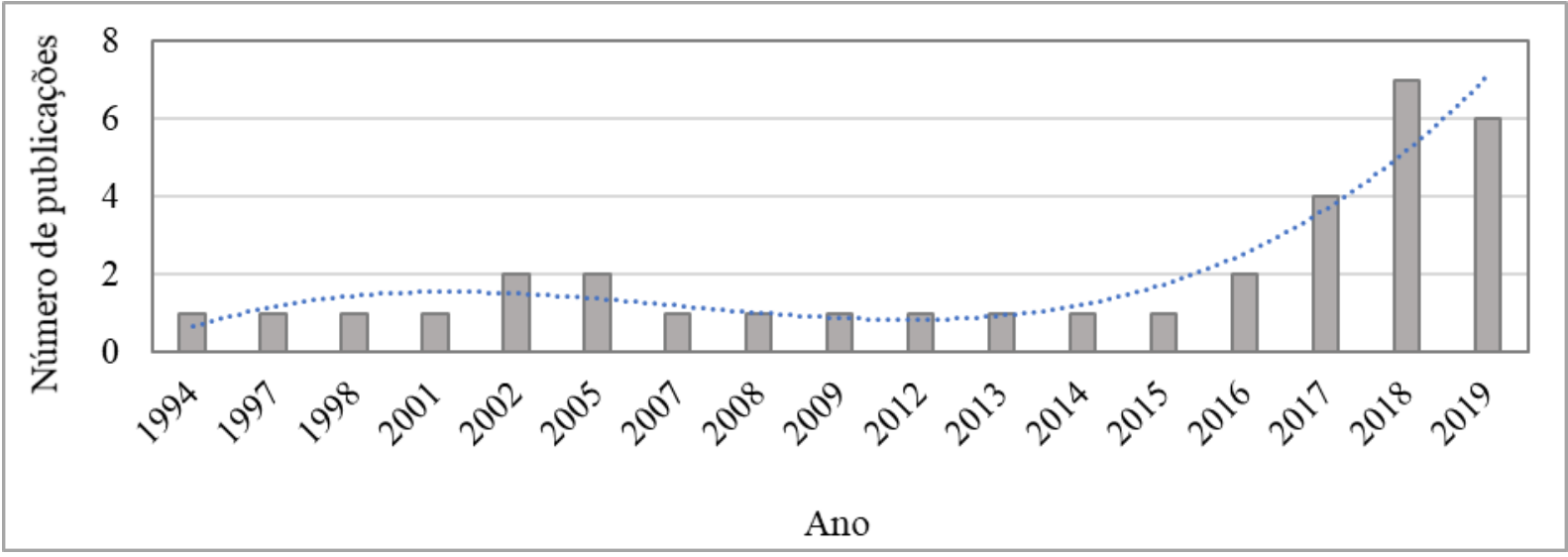

Fonte: Autores.

O crescimento do número de publicações a partir de 2017, principalmente daquelas vinculadas aos países da União Europeia, pode ser associado ao projeto CENTAUR (Cost Effective Neural Technique for Alleviation of Urban Flood Risk), criado em 2015 com financiamento desse bloco, que visava o desenvolvimento de um sistema de controle de fluxo de águas residuárias autônomo, descentralizado e econômico para reduzir o risco de enchentes urbanas (CENTAUR, 2016).

No Brasil, o crescimento das publicações a partir de 2017 pode ser resultante das discussões a respeito do Marco Regulatório do Saneamento Básico (Lei n 14.026/2020), que foram estimuladas por diversas políticas e programas de governo precedentes. Dessa forma, pode-se citar o lançamento em 2017 pela Agência Nacional de Águas (ANA) e pelo então Ministério das Cidades (atualmente denominado Ministério do Desenvolvimento Regional), do Atlas Esgotos: Despoluição de Bacias Hidrográficas. Além disso, o próprio diagnóstico anual do Sistema Nacional de Informações sobre Saneamento (SNIS) passou a coletar, a partir de 2015, os dados dos prestadores de serviço de drenagem e manejo de águas pluviais 
traçando-se um panorama nacional (SNIS, 2020).

Nota-se que as áreas do conhecimento com maior número de artigos correspondem aos Recursos hídricos (18\% dos artigos analisados), Ciências ambientais e ecologia (17\%), Engenharia (12\% dos artigos), Tecnologia (4\%) e Geografia, Saúde pública e Estudos urbanos, cada uma correspondendo a $2 \%$ dos artigos analisados (Figura 2). A coluna "Outros" representa as áreas do conhecimento com 1\% de publicações, tais como Agricultura, Administração pública, Ciência da computação e Ciências atmosféricas e meteorologia. Essa diversidade de campos do conhecimento reflete a multidisciplinaridade associada à drenagem urbana e às questões vinculadas ao saneamento, fomentando a ideia do planejamento integrado.

Figura 2 - Número de artigos científicos publicados por área do conhecimento no banco de dados Web of Science entre 1994 e 2019.

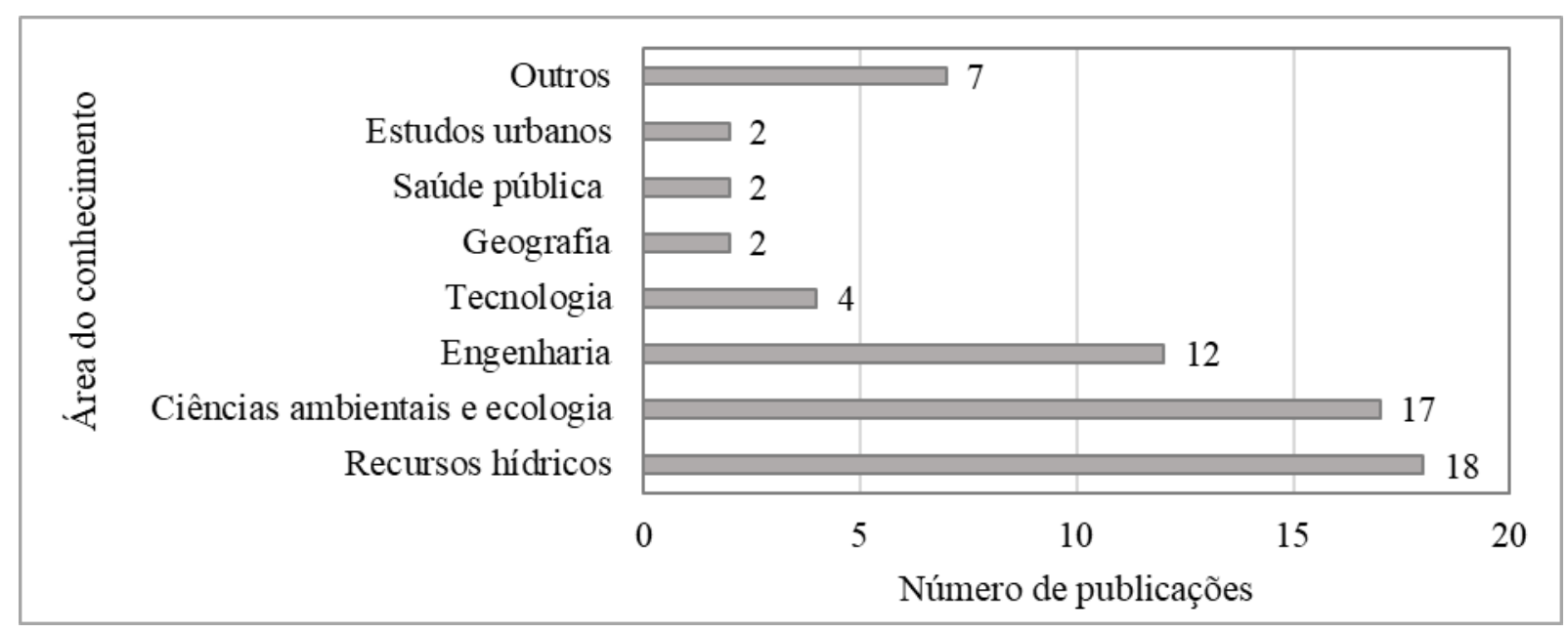

Fonte: Autores.

Um exemplo dessa forma de planejamento, ressaltado por Hillmann e Brierley (2005), relaciona-se à revitalização de rios, que em um passado recente, era executado unicamente pelo engenheiro de recursos hídricos. As premissas principais eram baseadas em obras e análises de resultados em trechos de rios, desconsiderando os aspectos de qualidade conjugados à intervenção proposta. Atualmente, os projetos de revitalização de rios buscam a transdisciplinariedade, a análise de impactos em termos de bacia hidrográfica, a participação da sociedade e das partes interessadas, dentre outros aspectos.

Ainda neste sentido, de acordo com Blumensaat et al. (2019), os tópicos emergentes vinculados às águas urbanas, incluindo cursos hídricos, envolverão, comumente, especialistas de diferentes áreas, como ecologistas e engenheiros, bem como profissionais da tecnologia da 
informação e cientistas da computação.

Quanto aos países com maior número de publicações no período analisado, nota-se que 14 trabalhos estão associados ao Brasil; 4 artigos referem-se à Inglaterra; França, Holanda e Espanha possuem 3 trabalhos cada um; enquanto Alemanha, China, Suécia e Suíça são citados em 2 artigos cada um (Figura 3). Faz-se importante destacar que alguns trabalhos faziam referência a mais de um país.

Figura 3 - Número de artigos científicos publicados por países entre 1994 e 2019.

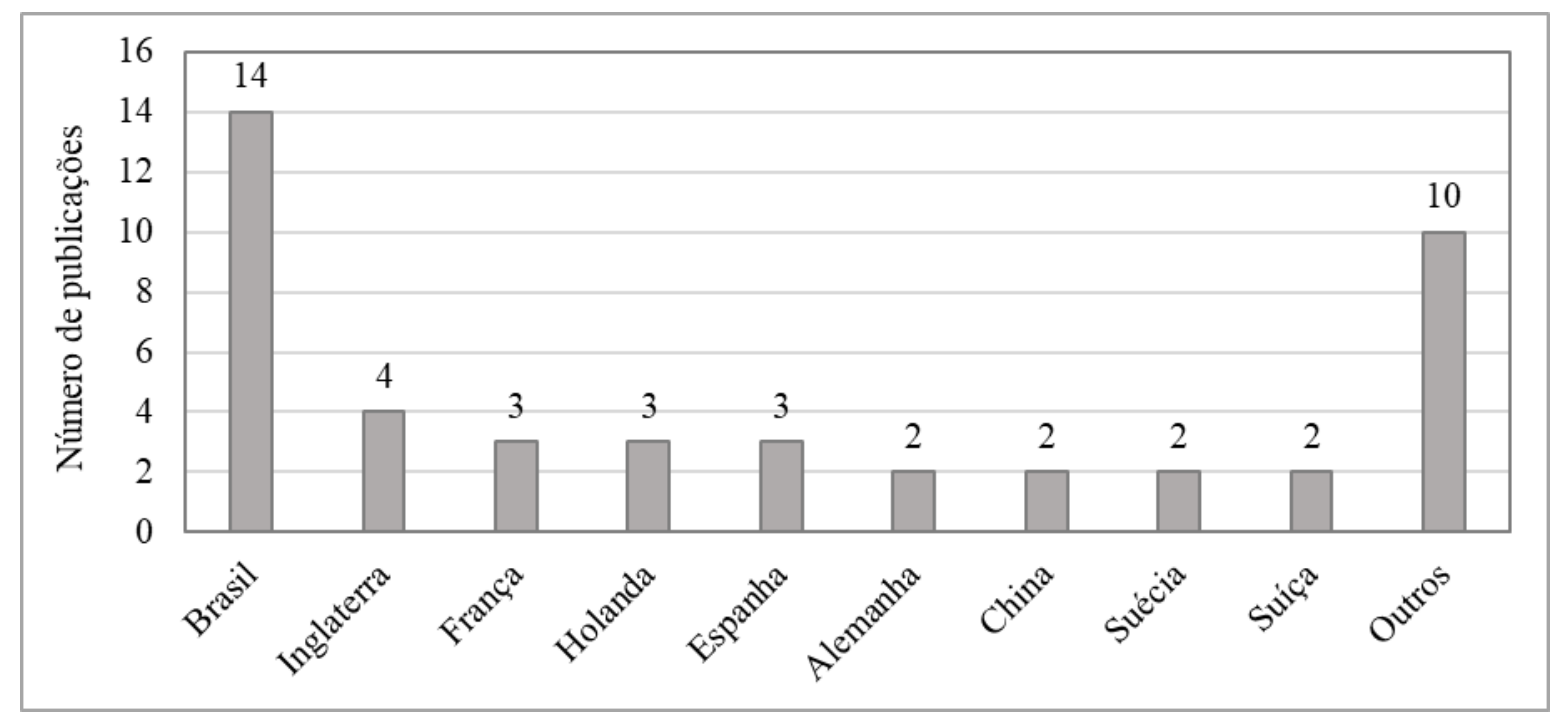

Fonte: Autores.

O maior número de publicações relacionadas ao Brasil pode ser justificado pela implementação tardia, já no século XIX, dos primeiros sistemas de saneamento. Além disso, de acordo com Morihama et al. (2012), em 1912, o Governo Federal preconizou o uso do sistema separador absoluto em todas as cidades do país, o que não foi atendido em sua plenitude em função da ocupação desordenada de vilas, favelas e áreas ribeirinhas; falta de rede coletora de esgotos e de drenagem pluvial próximo às residências e ligações clandestinas dos domicílios nas tubulações de infraestrutura urbana.

Em ambientes urbanos com ocupação desordenada, a existência de ligações clandestinas de tubulações de esgotos domésticos às redes de drenagem de água de chuva é comum, principalmente porque somente $60,9 \%$ dos domicílios urbanos brasileiros têm coleta de esgotos (SNIS, 2019). Dados do SNIS (2019) indicam que dentre os 3.603 municípios brasileiros $(64,7 \%$ do total) que participaram de uma pesquisa acerca do diagnóstico da situação da drenagem pluvial nas cidades brasileiras no ano de 2018, o sistema separador era utilizado por $54,8 \%$ das cidades, enquanto $24,6 \%$ usavam o sistema unitário (água pluvial e 
esgotos na mesma tubulação) e 17,6\% não possuíam qualquer dispositivo de drenagem.

A existência de ligações irregulares representa um dos maiores desafios do planejamento urbano atual, uma vez que não são visíveis a olho nu e dificilmente serão eliminadas quando ocorrer a concepção de novos projetos de sistemas de drenagem e de esgotos. Nesta acepção, pode-se citar o projeto de revitalização dos rios Tietê e Pinheiros, cuja principal crítica apontada por Morihama et al. (2012) estava relacionada à concepção do projeto, que desconsiderava a existência de um sistema unitário em grande parte da área projetada. Como a eliminação das ligações irregulares poderia inviabilizar financeiramente o projeto, esses autores sugeriram o uso de vertedouros na rede de drenagem, seguidos de reservatórios de acumulação, para atenuar a carga poluidora da vazão excedente que chegava aos corpos hídricos.

Afora a abordagem secundária da drenagem urbana no âmbito do saneamento ambiental (Silveira, 2002; Rego et al., 2013; Cunha \& Cannan, 2015; Gonçalves et al., 2017; Lima et al., 2017; Tasca et al., 2018) os artigos relacionados ao Brasil indexados no banco de dados Web of Science contemplavam a aplicação do modelo de uso de água urbana como ferramenta de apoio à gestão (Santos \& Benetti, 2014), assim como a proposição de uma abordagem integrada para o planejamento do saneamento e drenagem urbana (Soares et al., 2005) e o desenvolvimento do planejamento de macrodrenagem como elemento integrador da gestão de recursos hídricos (Obraczka et al., 2017).

Destacam-se ainda as temáticas vinculadas às doenças de veiculação hídrica (Aguiar et al., 2019); aos aspectos relacionados à prevenção de doenças e propostas de promoção da saúde (Souza \& Freitas, 2008); a contextualização do saneamento rural (Resende et al., 2018); a execução orçamentária vinculada ao plano diretor da cidade de Teresina, no estado do Piauí (Nascimento \& Gomes, 2018); e uma simulação do cenário associado ao aumento da impermeabilização na bacia hidrográfica e das cargas de sólidos suspensos totais, fósforo total e nitrato na Lagoa da Pampulha, Belo Horizonte/MG (Silva et al., 2019).

Considerando as palavras-chave citadas nos artigos analisados $(n=313)$, indicadas na Figura 4, nota-se que as mais mencionadas correspondem à "sustentabilidade" (sustainability), "drenagem urbana" (urban drainage), "gestão" (management), "sistemas" (systems), "saneamento" (sanitation), “água” (water), "cidades” (cities), "mudanças climáticas" (climate change), "saúde" (health) e "poluição" (pollution). Outras palavras como "uso do solo" (land-use), "indicadores" (indicators), "esgoto" (sewage) e "escoamento superficial" (runoff), "nutrientes" (nutrients) e "urbanização" (urbanization) foram citadas em menos de 4 trabalhos, atingindo porcentagens inferiores a 1,3\% 
Research, Society and Development, v. 9, n. 11, e1239119616, 2020

(CC BY 4.0) | ISSN 2525-3409 | DOI: http://dx.doi.org/10.33448/rsd-v9i11.9616

Figura 4 - Número de artigos científicos publicados por área do conhecimento entre 1994 e 2019.

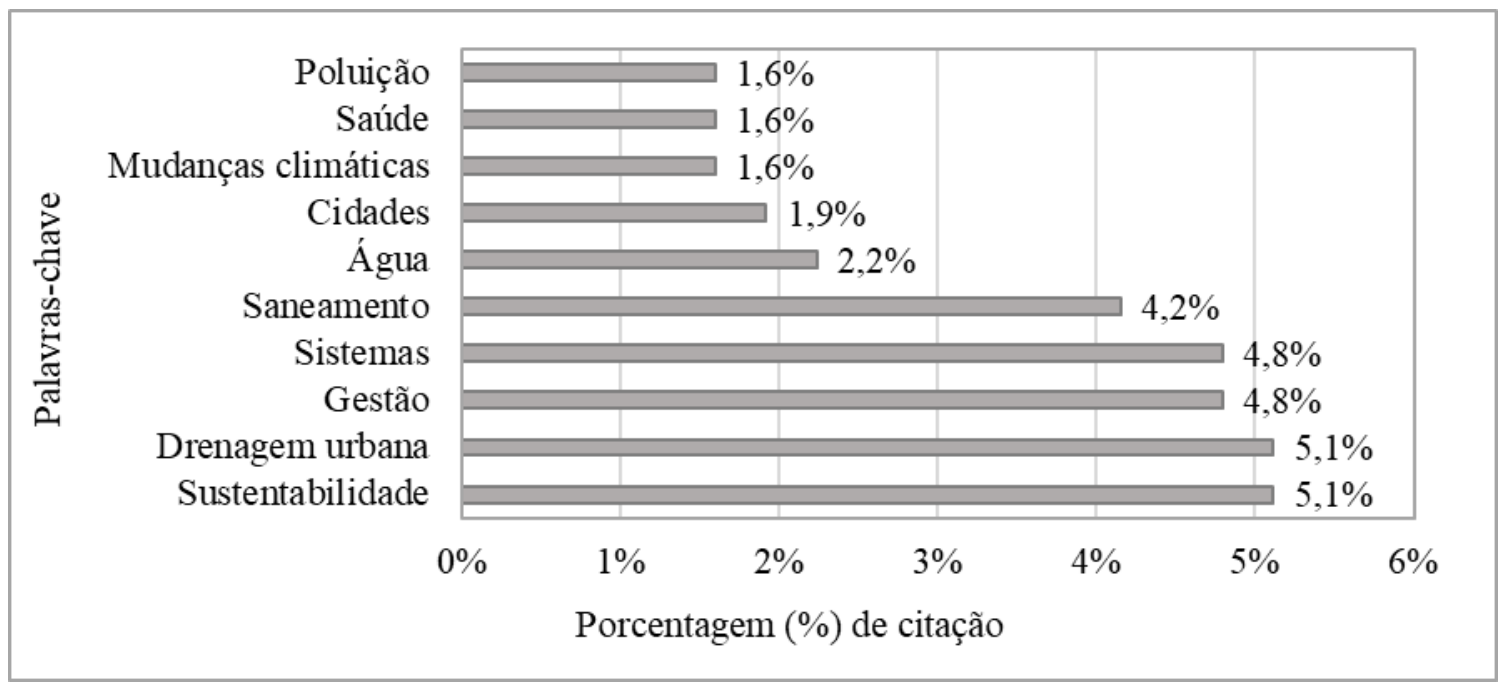

Fonte: Autores.

Uma maior frequência observada com relação às palavras "drenagem urbana" e "saneamento" era esperada, visto que correspondem às palavras utilizadas na pesquisa realizada no banco de dados Web of Science.

As palavras-chave "sustentabilidade" (5,1\% de citações), "gestão" e "sistemas" (4,8\% de citações cada uma), "saneamento" (4,2\% de citações), "água" ( $2,2 \%$ de citações) e “cidades" (1,9\% de citações) podem ser associadas à busca de uma abordagem integrada para a gestão de sistemas de água urbanos, abrangendo o abastecimento de água, drenagem urbana, esgotamento sanitário e resíduos sólidos.

Essa abordagem integrada, entre outros aspectos, deve: (i) considerar todas as partes, ou componentes, do sistema, reconhecendo-o como um sistema integrado, (ii) considerar todos os requisitos relacionados à água, tanto antrópicos como ecológicos, (iii) considerar o contexto local, incluindo as perspectivas ambientais, sociais, culturais e econômicas; (iv) incluir todas as partes interessadas no processo e (v) buscar a sustentabilidade equilibrando as necessidades ambientais, sociais e econômicas a curto, médio e longo prazos (Mitchell, 2004, 2006).

Há diversos nomes para essa nova abordagem como, por exemplo, BMP (Best Management Practices - Melhores Práticas de Gerenciamento) nos Estados Unidos; SUDS (Sustainable Urban Drainage Systems - Sistemas de Drenagem Urbana Sustentável) no Reino Unido; LID (Low Impact Development - Desenvolvimento de Baixo Impacto); e WSUD (Water Sensitive Urban Design - Projeto Urbano Sensível à Água). 
Research, Society and Development, v. 9, n. 11, e1239119616, 2020

(CC BY 4.0) | ISSN 2525-3409 | DOI: http://dx.doi.org/10.33448/rsd-v9i11.9616

Enquanto as abordagens convencionais de engenharia coletam e conduzem a água para fora da bacia hidrográfica o mais rapidamente possível através dos sistemas de transporte (canais, tubos, bombas e reguladores), a abordagem integrada mantém a água na área da bacia hidrográfica o maior tempo possível, utilizando para isso ecossistemas naturais e seus processos (Ahiablame et al., 2012).

De um modo geral, as práticas associadas à essa abordagem objetivam a redução dos volumes escoados, a melhoria da infiltração e/ou armazenamento de águas pluviais, e a remoção de poluentes presentes nas águas pluviais (Davis \& Masten, 2016; Miguez et al., 2018). Destaca-se ainda que essa mudança de paradigma nos projetos de drenagem possibilitou o emprego de mecanismos de escoamento naturais, tais como valas e trincheiras de infiltração, lagoas de detenção, telhados verdes, reservatórios de acumulação e pavimentos permeáveis (Butler \& Davies, 2004).

Esses mecanismos, também denominados técnicas compensatórias em drenagem urbana, permitem a continuidade do desenvolvimento urbano sem a geração de custos excessivos, possibilitando ainda a modificação do sistema de drenagem resultante do crescimento urbano, assim como o tratamento das questões envolvendo a drenagem pluvial associado àquelas de origem urbanística (Baptista et al., 2011). Contudo, esses autores ressaltam que a análise acerca da viabilidade dessas técnicas deve ser fundamentada nos seus princípios de funcionamento; formas de alimentação, armazenamento e esvaziamento; e nos requisitos e restrições de uso.

Dentre os critérios que condicionam a viabilidade das técnicas compensatórias podem ser destacados os aspectos: (i) físicos, tais como topografia local, existência de exutório permanente, capacidade de infiltração do solo, nível das águas subterrâneas, estabilidade do subsolo e aporte permanente de água; (ii) urbanísticos e de infraestrutura, representados por exemplo, pela disponibilidade de espaço, inclinação e forma dos telhados e redes existentes; (iii) socioeconômicos; e (iv) sanitários e ambientais (Baptista et al., 2011).

Com relação a estes últimos aspectos, devem ser evidenciados o risco de poluição, risco das águas carrearem material fino e o risco sanitário. O risco de poluição dos solos e das águas é baseado em duas avaliações: a qualidade das águas de escoamento que serão evacuadas e a vulnerabilidade do meio receptor, como corpos d'água superficiais, nível freático e o solo. O risco de carreamento pelas águas de material fino, proveniente, por exemplo, de solos pouco protegidos pela vegetação ou descobertos e taludes com declividade acentuada, aumentam a probabilidade de colmatação e risco de falha do sistema (principalmente às obras de infiltração e para as bacias de detenção), fazendo-se necessária a 
utilização de dispositivos de decantação, a montante do local de implantação das técnicas. Por fim, o risco sanitário está associado, principalmente, à possível estagnação de água em determinadas técnicas, podendo favorecer o desenvolvimento de organismos vetores de doenças (Baptista et al., 2011).

Nota-se na Figura 4 que as palavras-chave "mudanças climáticas", "poluição" e "saúde" foram citadas em 1,6\% dos artigos analisados. Com relação às mudanças nas condições climáticas, sabe-se que o aumento da intensidade das chuvas, alterações nos padrões de precipitação e eventos climáticos mais extremos, resultam na exposição dos sistemas de drenagem urbana a chuvas intensas com uma alta frequência, podendo acarretar em um aumento significativo na frequência e magnitude das inundações urbanas (Dong et al., 2017).

No entanto, salienta-se que além dessas ameaças externas, as inundações urbanas podem ser decorrentes de problemas internos, como o mau funcionamento de equipamentos (como bombas, reservatórios ou tubulação), colapso do sistema de esgoto, sobrecarga e deterioração dos sistemas (esgoto e drenagem) e existência de sedimentação (Mugume et al., 2015).

Já a "poluição" está comumente relacionada aos transbordamentos dos sistemas de esgoto e ao contato direto com seu despejo direto em galerias a céu aberto. Os impactos negativos a longo prazo variam desde a contaminação de sedimentos dos leitos dos rios à eutrofização dos corpos hídricos. Entretanto, destacam-se os impactos de curto prazo, que podem levar a condições letais para organismos aquáticos (Riechel et al., 2016; 2020).

Há diversos parâmetros utilizados para a caracterização das águas quanto à suas características físicas, químicas e biológicas. O Quadro 1 exibe uma classificação dos variados tipos de poluentes considerando sua incidência no meio e os parâmetros associados.

Afora a poluição, o adequado equacionamento da drenagem urbana relaciona-se diretamente à ocorrência de doenças. A ocupação de áreas periféricas das cidades em países subdesenvolvidos, em regiões com situação precária de infraestrutura, como vilas, favelas e áreas ribeirinhas, exibe diversas vezes nexo causal com os problemas de saúde dos moradores desses locais.

Ao avaliarem os fatores socioambientais e climáticos que influenciavam diretamente a proliferação da dengue no município de Itacoatiara (Amazonas), Almeida e Castro (2018) identificaram que o risco de disseminação da doença era mais alto em locais com precariedade nos serviços de drenagem pluvial (formação de água parada), associados às temperaturas entre 24 e $35^{\circ} \mathrm{C}$, precipitações de até $80 \mathrm{~mm}$ e umidade entre 70 e $80 \%$. 
Quadro 1 - Classificação dos diferentes tipos de poluentes em relação à sua incidência no meio.

\begin{tabular}{|c|c|c|c|}
\hline $\begin{array}{c}\text { Tipos de } \\
\text { poluentes }\end{array}$ & $\begin{array}{c}\text { Impactos sobre o meio e } \\
\text { sobre os usos da água } \\
\end{array}$ & Parâmetros associados & $\begin{array}{c}\text { Origens possíveis dos } \\
\text { poluentes }\end{array}$ \\
\hline Partículas & $\begin{array}{l}\text { Colmatação de leitos ou de } \\
\text { estruturas de infiltração, } \\
\text { aumento da turbidez, vetor de } \\
\text { outros poluentes }\end{array}$ & $\begin{array}{c}\text { Sólidos suspensos, sólidos } \\
\text { suspensos voláteis, sólidos } \\
\text { suspensos totais, materiais } \\
\text { decantáveis, turbidez } \\
\end{array}$ & $\begin{array}{l}\text { Erosão de solos, lixiviação } \\
\text { de superfícies, efluentes } \\
\text { domésticos e industriais }\end{array}$ \\
\hline Orgânicos & $\begin{array}{l}\text { Desoxigenação do ambiente, } \\
\text { desenvolvimento excessivo de } \\
\text { bactérias }\end{array}$ & $\mathrm{DQO}, \mathrm{DBO}_{5}, \mathrm{COT}, \mathrm{COD}$ & $\begin{array}{l}\text { Águas residuárias urbanas, } \\
\text { industriais ou agrícolas }\end{array}$ \\
\hline Nutrientes & $\begin{array}{c}\text { Eutrofização das águas } \\
\text { superficiais, consumo de } \\
\text { oxigênio, efeitos tóxicos, } \\
\text { dificuldade para a produção } \\
\text { de água potável }\end{array}$ & $\begin{array}{c}\mathrm{NO}_{2}^{-}, \mathrm{NO}_{3}^{-} \text {, nitrogênio } \\
\text { total Kjeldahl, nitrogênio } \\
\text { orgânico, nitrogênio total, } \\
\mathrm{PO}_{4}^{3-}, \mathrm{PT}\end{array}$ & $\begin{array}{c}\text { Escoamento sobre zonas de } \\
\text { utilização de adubos, criação } \\
\text { de animais, produção de } \\
\text { adubos, produtos de } \\
\text { degradação da matéria } \\
\text { orgânica } \\
\end{array}$ \\
\hline Tóxicos & $\begin{array}{l}\text { Toxicidade, inibição da vida } \\
\text { aquática, destruição da flora }\end{array}$ & $\begin{array}{l}\text { Metais pesados, fenóis, } \\
\text { cianuretos, } \\
\text { hidrocarbonetos }\end{array}$ & $\begin{array}{l}\text { Rejeitos industriais, } \\
\text { circulação de automóveis, } \\
\text { corrosão dos materiais de } \\
\text { construção (metais) }\end{array}$ \\
\hline Bioacumulativos & $\begin{array}{c}\text { Acumulação na cadeia trófica, } \\
\text { toxicidade }\end{array}$ & $\begin{array}{c}\text { Pesticidas } \\
\text { (organoclorados, } \\
\text { organofosforados, } \\
\text { organometálicos), PCB } \\
\text { (policlorobifenil) } \\
\end{array}$ & $\begin{array}{l}\text { Agricultura, isolantes e } \\
\text { materiais plásticos }\end{array}$ \\
\hline Bacteriológicos & $\begin{array}{c}\text { Risco para a balneabilidade, } \\
\text { dificuldades para a produção } \\
\text { de água potável }\end{array}$ & $\begin{array}{c}\text { Coliformes, estreptococos, } \\
\text { salmonelas, E. coli, vírus }\end{array}$ & $\begin{array}{l}\text { Poluição doméstica, criação } \\
\text { de animais }\end{array}$ \\
\hline Minerais & $\begin{array}{l}\text { Comprometimento à produção } \\
\text { de água potável, agressividade } \\
\text { para as canalizações, } \\
\text { dispersão de metais pesados }\end{array}$ & $\begin{array}{c}\mathrm{Cl}^{-}, \mathrm{Na}^{+}, \mathrm{K}^{+}, \mathrm{Mg}^{2+}, \mathrm{Ca}^{2+}, \\
\mathrm{CO}_{3}{ }^{2-}, \mathrm{HCO}^{3-}\end{array}$ & $\begin{array}{c}\text { Efluentes de indústrias que } \\
\text { usam sais poluição } \\
\text { doméstica }\end{array}$ \\
\hline Radioatividade & $\begin{array}{l}\text { Acumulação na cadeia trófica, } \\
\text { toxicidade }\end{array}$ & $\begin{array}{c}\text { Contagem dos raios e das } \\
\text { partículas } \alpha_{s} \beta, \gamma\end{array}$ & Hospitais, indústrias \\
\hline
\end{tabular}

Fonte: Baptista et al. (2011, p. 64).

Ressalta-se ainda que, nesses locais há, comumente, outros problemas conjugados à uma drenagem pluvial inadequada, tais como a frequente incidência de resíduos sólidos urbanos e esgoto a céu aberto. Como consequência desses aspectos podem ser salientadas a proliferação de vetores de doenças, como insetos e ratos, além da possibilidade de contato direto dos seres humanos com agentes transmissores de doenças em meio aquático.

O Quadro 2 apresenta, de forma sucinta, alguns exemplos de doenças decorrentes de uma drenagem pluvial inadequada. De modo geral, essas doenças podem ser classificadas de acordo com a sua relação com a água. Tem-se, assim, as doenças com fonte na água, que dependem desse meio para sua transmissão (como cólera, salmonela e leptospirose); relacionadas à ausência de higiene, que dependem da educação da população e da disponibilidade de água considerada segura; e aquelas associadas à água, nas quais o agente 
utiliza a água para se desenvolver (Tucci, 2005).

Quadro 2 - Doenças de veiculação hídrica associadas à drenagem.

\begin{tabular}{|c|c|}
\hline Modo de favorecimento de contaminação/transmissão & Doença \\
\hline Vetores aéreos ligados à presença de água estagnada & $\begin{array}{c}\text { Febre amarela } \\
\text { Dengue } \\
\text { Filariose } \\
\text { Malária }\end{array}$ \\
\hline Desenvolvimento de agentes transmissores em meio aquático & Esquistossomose \\
\hline Contato direto facilitado por inundações e presença de água \\
estagnada & Leptospirose \\
\hline $\begin{array}{c}\text { Ingestão de água contaminada por agentes etiológicos presentes } \\
\text { em áreas úmidas e inundações que entram nos sistemas de } \\
\text { distribuição de água }\end{array}$ & $\begin{array}{c}\text { Cólera } \\
\text { Febre tifoide } \\
\text { Outras diarreias }\end{array}$ \\
\hline $\begin{array}{c}\text { Doenças transmitidas por contato direto com solo contaminado - } \\
\text { contaminação favorecida por inundações }\end{array}$ & $\begin{array}{c}\text { Hepatite A (água) } \\
\text { Ascaridíase (água) } \\
\text { Tricuríase (água) } \\
\text { Ancilostomose (água e solo) }\end{array}$ \\
\hline
\end{tabular}

Fonte: Modificado de Butler e Davies (2004).

Os mosquitos são responsáveis pela disseminação de diferentes doenças, sendo que cada espécie seleciona diferentes tipos de corpos d'água para a sua reprodução (Butler \& Davies, 2004). A malária, mais conhecida dessas doenças, é transmitida pela fêmea do mosquito Anopheles, que geralmente não se reproduz em águas muito poluídas, mas pode se multiplicar em áreas alagadas e/ou mal drenadas e poças. Já os mosquitos Culex, vetores da filariose que pode levar à elefantíase, utilizam a água poluída (por exemplo, fossa e água estagnada).

A esquistossomose é uma doença infecto-parasitária originária da África e da Ásia, sendo que das seis espécies de Schistosoma que podem parasitar o homem, apenas o $S$. mansoni ocorre nas Américas do Sul e Central. Essa doença, que possui como hospedeiros intermediários caramujos de água doce do gênero Biomphalaria, pode ser adquirida através das mucosas e da pele em contato com águas contendo formas infectantes desse parasita. Os sintomas dependem da localização, da quantidade do parasita nos órgãos e das reações do organismo humano, assim como da resposta ao tratamento. Dessa forma, pode ser uma doença assintomática ou sintomática, nesse último caso incluindo dermatites, alterações hepáticas e paraplegia (Brasil, 2014).

A leptospirose corresponde à uma zoonose causada por bactérias do gênero Leptospira que podem ser transmitidas tanto pelo contato com urina de animais infectados ou pelo contato com água e lama contaminadas pela bactéria. Esse microrganismo penetra o 
organismo através das mucosas, lesões na pele ou pela pele íntegra imersa em água por longo período. Destaca-se que apesar das leptospiras poderem permanecer viáveis por mais de 150 dias, o período de sobrevida varia de acordo com o pH (são sensíveis a pH ácido, menor do que 6,8), temperatura, salinidade e grau de poluição (Brasil, 1995).

A cólera corresponde à uma doença infecciosa intestinal aguda causada pela enterotoxina Vibrio cholerae O1 ou O139, um microrganismo natural do ecossistema aquático. Esses microrganismos penetram no organismo humano por via oral e se alojam no intestino delgado. A alcalinidade desse ambiente constitui um meio propício para sua proliferação e, posteriormente, liberação da exotoxina que atuará sobre as células da mucosa intestinal, resultando em sintomas diversos como diarreia profusa, acidose e colapso circulatório (Brasil, 2010a).

A febre tifoide é uma doença bacteriana aguda causa pela Salmonella enterica sorotipo Typhi. As formas de transmissão dessa doença estão associadas ao contato direto com as mãos do doente ou portador ou pela ingestão de água e/ou alimentos contaminados por fezes ou urina de pessoas doentes. Dentre os sintomas clássicos podem ser citados febre alta, malestar geral, cefaleia, dor abdominal, falta de apetite, obstipação intestinal ou diarreia, bradicardia relativa (dissociação pulso-temperatura), manchas rosadas no tronco e tosse seca (Brasil, 2010b).

Já as larvas de helmintos, como aquelas associadas à ascaridíase e ancilostomose, podem ser transmitidas pelo contato de fezes infectadas com o solo. Assim, quando especialmente as crianças entram em contato com águas pluviais contaminadas pela presença dessas fezes ou ingerem os ovos infectantes desses organismos, podem ser acometidas por essas parasitoses intestinais (Brasil, 2004).

Por fim, Freitas e Ximenes (2012) destacam associados às inundações o risco de morte por afogamento e as doenças pós-traumáticas, como por exemplo a depressão e transtornos psicológicos após esses eventos, tais como insônia, amnésia, irritabilidade e fobias.

Além das doenças de veiculação hídrica, faz-se importante destacar o papel do escoamento na disseminação de antibióticos, bactérias resistentes a antibióticos e genes de resistência a antibióticos em áreas urbanas, o qual, de acordo com Almakki et al. (2019), ainda é pouco conhecido. Dessa forma, os autores salientam que a saúde ambiental é parte integrante de uma estratégia mundial de controle de doenças infecciosas e que o escoamento urbano se enquadra no âmbito do controle global de infecções.

Ainda neste sentido, Lee et al. (2020) ao analisarem a qualidade das águas urbanas, comunidades microbianas e potenciais implicações para a saúde pública em Columbus (Ohio, 
EUA), observaram que chuvas intensas e de curta duração resultaram em uma maior contaminação fecal (maior concentração de E. coli) em águas pluviais. Com relação às espécies microbianas, uma diversidade de genes de resistência a antibióticos (como $\beta$ lactâmico), bactérias potencialmente patogênicas (por exemplo, Salmonella enterica Typhimurium), fungos (por exemplo, Scedosporium apiospermum) e protistas (por exemplo, Acanthamoeba palestinensis) foram encontrados em fluxos de águas pluviais urbanas que são lançados em cursos hídricos adjacentes.

Nota-se assim que os poluentes carreados pelo escoamento superficial durante eventos de chuva podem constituir um grande contribuinte para os problemas de qualidade da água em áreas urbanas (Behera et al., 2006; Richardson \& Tripp, 2006). Apesar disso, o "escoamento superficial" foi citado como palavra-chave em apenas 2 artigos analisados.

Um aspecto importante relacionado ao escoamento superficial, que não foi citado como palavra-chave nos artigos analisados, corresponde à primeira descarga de poluentes (também conhecido como first flush). Esse fenômeno consiste no carreamento de uma proporção maior das cargas poluentes no início de um evento de chuva (Lee et al., 2002; Sansalone \& Cristina, 2004).

Dentre os diversos fatores que influenciam nesse fenômeno podem ser destacados o tipo de poluente, a área de captação, a área impermeável contribuinte e a intensidade da chuva (Lee et al., 2002). De modo geral, os principais poluentes incluem matéria visível, sólidos suspensos, materiais oxigenantes, nutrientes, microrganismos patogênicos e compostos tóxicos, como metais traço, pesticidas e hidrocarbonetos. Faz-se importante salientar que todas essas substâncias impõem consideráveis estresses físicos, químicos e biológicos nas águas receptoras, afetando o meio aquático, a vida e saúde humana, além de prejudicar os usos múltiplos dos recursos hídricos (Behera et al., 2006).

Nascimento et al. (1999) compararam dados referentes à carga média de poluição presente no escoamento pluvial e nos esgotos sanitários brutos de duas bacias hidrográficas francesas considerando intervalos de tempo horário, diário e anual, e as informações sobre as cargas por unidade de área para efluentes de águas pluviais derivados de dados relacionados ao Reino Unido.

Apesar da impossibilidade de generalização, os autores concluíram que as cargas médias referentes à demanda bioquímica de oxigênio $\left(\mathrm{DBO}_{5}\right)$, demanda química de oxigênio (DQO), sólidos totais e nitrogênio total Kjeldahl (NTK) são superiores nos esgotos sobretudo para as escalas anual e diária (Quadro 3). Por outro lado, considerando os metais $\mathrm{Pb}, \mathrm{Zn}, \mathrm{Hg}$ e Cd, a carga de poluição foi superior nas águas pluviais para as escalas horária e diária. 
(CC BY 4.0) | ISSN 2525-3409 | DOI: http://dx.doi.org/10.33448/rsd-v9i11.9616

Quadro 3 - Comparação de cargas de poluição de origem pluvial (AP) e de esgoto doméstico (ED).

\begin{tabular}{|c|c|c|c|c|}
\hline \multirow{2}{*}{ Parâmetro } & AP/ED & AP/ED & AP/ED & AP \\
\cline { 2 - 5 } & ano & dia & hora & (kg/área impermeável/ano) \\
\hline Sólidos totais & 0,50 & 0,50 & 50,00 & 487 \\
\hline $\mathrm{DBO}_{5}$ & 0,04 & 0,17 & 4,00 & 59 \\
\hline $\mathrm{DQO}$ & 0,11 & 0,50 & 12,00 & 358 \\
\hline $\mathrm{NTK}$ & 0,04 & 0,14 & 3,50 & - \\
\hline $\mathrm{Pb}$ & 27,00 & 80,00 & 2000,00 & 1,15 \\
\hline $\mathrm{Zn}$ & 1,00 & 4,00 & 100,00 & \\
\hline $\mathrm{Hg}$ & 1,00 & 7,00 & - & \\
\hline $\mathrm{Cd}$ & 1,00 & 5,00 & - & \\
\hline
\end{tabular}

Fonte: Nascimento et al. (1999).

Percebe-se, dessa forma, que eventos chuvosos representados nas escalas horária e diária podem resultar em problemas de contaminação aguda, enquanto problemas de contaminação crônica podem ser associados aos valores médios de carga anual.

Considerando essa perspectiva, Gasperi et al. (2014) analisaram a concentração de diferentes contaminantes, como hidrocarbonetos policíclicos aromáticos (PAHs), poluentes pouco ou não documentados, como nonilfenol e etoxilatos de octilfenol (NPnEO e OPnEO), bisfenol A (BPA), éteres difenílicos polibromados (PBDEs), pesticidas e vários metais de relevância ( $\mathrm{Zn}, \mathrm{Cu}, \mathrm{Pb}, \mathrm{As}, \mathrm{Ti}, \mathrm{Sr}, \mathrm{V}$, dentre outros), nas águas pluviais de três bacias urbanas localizadas em três cidades francesas, caracterizadas por diferentes padrões de uso do solo.

De modo geral, esses autores verificaram que a maioria dos metais estava associada à fase particulada: (i) $>50 \%$ para $\mathrm{As}, \mathrm{Cd}, \mathrm{Mo}, \mathrm{Ni}, \mathrm{V}, \mathrm{Cu}$ e $\mathrm{Zn}$; e (ii) $>80 \%$ para $\mathrm{Co}, \mathrm{Cr}, \mathrm{Pb}$ e Ti. Por outro lado, quando considerados os poluentes orgânicos, Gasperi et al. (2014) observaram que suas distribuições entre as fases dissolvidas e particuladas dependiam fortemente de suas propriedades químicas e físicas. Além disso, os autores salientaram que a ocorrência desses últimos poluentes e de outras substâncias como BPA e PBDEs, está correlacionada à lixiviação de superfícies urbanas, edifícios e veículos, recomendando assim novas pesquisas associadas à uma investigação detalhada das fontes reais desses compostos.

\subsection{Artigos mais citados}

Os três artigos mais citados dentre aqueles que compõem a amostra utilizada nessa pesquisa podem ser observados no Quadro 4. Apesar do trabalho publicado por Butler e Parkinson (1997) possuir o maior número de citações (correspondendo a 91), o artigo de Hoekstra et al. (2018) possui a maior média de citações por ano $(12,67)$. 
Quadro 4 - Artigos mais citados no banco de dados Web of Science a partir de pesquisa com as palavras-chave "urban drainage" e "sanitation".

\begin{tabular}{|c|c|c|c|c|c|}
\hline Autores & Título do artigo & Periódico & $\begin{array}{c}\text { Ano de } \\
\text { publicação }\end{array}$ & $\begin{array}{c}\text { Total de } \\
\text { citaçóes }\end{array}$ & $\begin{array}{c}\text { Média por } \\
\text { ano }\end{array}$ \\
\hline $\begin{array}{c}\text { Butler, D.; } \\
\text { Parkinson, J. }\end{array}$ & $\begin{array}{c}\text { Towards sustainable urban } \\
\text { drainage }\end{array}$ & $\begin{array}{c}\text { Water Science and } \\
\text { Technology }\end{array}$ & 1997 & 91 & 3,79 \\
\hline $\begin{array}{c}\text { Huang, D.; Bader, } \\
\text { H.; Scheidegger, } \\
\text { R.; Schertenleib, } \\
\text { R.; Gujer, W. }\end{array}$ & $\begin{array}{c}\text { Confronting limitations: New } \\
\text { solutions required for urban } \\
\text { water management in Kunming } \\
\text { City }\end{array}$ & $\begin{array}{c}\text { Journal of } \\
\text { Environmental } \\
\text { Management }\end{array}$ & 2007 & 48 & 3,43 \\
\hline $\begin{array}{c}\text { Hoekstra, A. Y.; } \\
\text { Buurman, J.; van } \\
\text { Ginkel, K. C. H. }\end{array}$ & Urban water security: A review & $\begin{array}{c}\text { Environmental } \\
\text { Research Letters }\end{array}$ & 2018 & 38 & 12,67 \\
\hline
\end{tabular}

Fonte: Autores.

O trabalho de Butler e Parkinson (1997) reavalia a oferta de serviços de drenagem urbana sob a perspectiva do desenvolvimento sustentável. Neste contexto, a drenagem urbana sustentável deve possuir como principais objetivos, em ordem de prioridade: (i) a manutenção de uma barreira de saúde pública eficaz; (ii) evitar inundações locais ou distantes; (iii) a prevenção da degradação/poluição da água, ar e solo; (iv) minimização da utilização de recursos naturais (por exemplo, água, energia, materiais); (v) ser confiável a longo prazo e adaptável às necessidades futuras, ainda desconhecidas; (vi) permitir a acessibilidade da comunidade e; (vii) ser aceita socialmente.

$\mathrm{Na}$ busca por soluções economicamente viáveis, flexíveis às mudanças e higienicamente aceitáveis sob condições variáveis, Butler e Parkinson (1997) sugerem três estratégias fundamentais que devem ser perseguidas: (1) a redução da dependência do uso da água como meio de transporte de resíduos; (2) a eliminação da mistura de águas residuais industriais com águas residuais domésticas, e (3) eliminação da combinação entre o escoamento de águas pluviais e águas residuais.

Apesar do investimento e dos esforços empregados visando o controle da poluição, os ambientes aquáticos urbanos são continuamente degradados em diferentes regiões no mundo. Assim, a fim de identificar as limitações das práticas atuais de gestão de água urbana e para estimular uma intervenção proativa, Huang et al. (2007) analisaram o fluxo de material (água, fósforo total e nitrogênio total) no sistema de água urbano na cidade de Kunming (capital da província de Yunnan, no sudoeste da China), que tem tentado melhorar seu ambiente aquático urbano desde o final dos anos de 1980.

A cidade de Kunming está localizada nas proximidades do sexto maior corpo de água doce da China, o Lago Dianchi. Devido a gravidade de sua poluição e o seu papel importante 
no abastecimento de água, clima local, controle de enchentes e turismo, o Lago Dianchi foi incluído em uma lei chinesa de restauração de lagos.

Os resultados obtidos por Huang et al. (2007) indicaram que a eficiência do tratamento de águas residuais era de cerca de $25 \%$, sendo que a emissão de fósforo total para o Lago Dianchi era superior a 25 vezes sua tolerância estimada. Desse modo, os autores destacam que o alcance de um ambiente hídrico urbano sustentável em Kunming não pode ser alcançado com a abordagem até então adotada, baseada em avanços incrementais e técnicas convencionais, devido às limitações técnicas dos sistemas convencionais de drenagem e tratamento urbano. Assim, os autores ressaltam a necessidade de novas pesquisas visando o desenvolvimento do saneamento doméstico orientado para o controle das fontes de poluição e sua aplicação, essa última existente apenas em uma escala piloto.

O artigo de revisão bibliográfica elaborado por Hoekstra et al. (2018) salienta, dentre outros aspectos, os diferentes focos abordados na literatura quanto a "segurança hídrica" (bem-estar, equidade, sustentabilidade e riscos relacionados à água), evidenciando que esse termo tem sido utilizado em substituição à expressão "gestão integrada e sustentável da água" como reflexo das mudanças observadas quanto às diferentes percepções e cerne da temática.

De acordo com Hoekstra et al. (2018), na metade da década de 1980, utilizava-se a expressão "gestão integrada dos recursos hídricos" para destacar que a abordagem dos problemas hídricos não seria adequada na ausência de um planejamento holístico, considerando os sistemas hídricos como um todo. Por volta de 1990, o termo "gestão sustentável da água" se tornou popular, inspirado pela aceitação da ideia de desenvolvimento sustentável após a publicação do relatório de Brundtland.

Na década de 2010, o termo "gestão adaptativa das águas" tornou-se popular, inspirado pela necessidade de adaptação às mudanças climáticas, sendo em sequência utilizado de forma mais ampla, referindo-se à necessidade de se adaptar continuamente e responder com flexibilidade às mudanças em geral.

Além disso, Hoekstra et al. (2018) realizaram um inventário das múltiplas perspectivas envolvendo a segurança das águas urbanas, podendo ser ressaltadas as perspectivas: (i) disciplinares (como engenharia, meio ambiente, políticas públicas e saúde pública); (ii) orientadas para o problema (tais como escassez de água, inundações e poluição da água); (iii) orientadas por objetivos (por exemplo, melhoria do abastecimento de água e saneamento, melhoria do tratamento de esgoto e águas residuais, drenagem urbana adequada e segurança contra inundações); (iv) relacionadas à integração das questões hídricas ao planejamento urbano e (v) envolvendo políticas coerentes em diferentes instituições governamentais. 
Os autores ainda destacaram o artigo de Brown et al. (2009) que, ao analisarem as mudanças nos arranjos institucionais e tecnológicos que apoiaram as práticas de gestão hídrica urbana da Austrália nos últimos 200 anos, propuseram uma estrutura para a compreensão da transição da gestão hídrica urbana visando condições sustentáveis.

A Figura 5 exibe os seis estágios subsequentes relacionados à "estrutura de transição da gestão de águas urbanas" identificados por Brown et al. (2009). O primeiro estágio corresponde à cidade do abastecimento de água, que possui foco no abastecimento de água seguro e eficaz. O segundo estágio é representado pela cidade do esgoto, com ênfase adicional no esgoto como uma resposta aos surtos epidêmicos de doenças. No terceiro estágio tem-se a cidade drenada, evidenciando a drenagem urbana como consequência do aumento dos danos causados pelas águas pluviais. O quarto estágio corresponde à cidade hidroviária, apresentando maior foco na limpeza de corpos hídricos e tratamento de águas residuais como efeito do aumento da poluição das águas. O quinto estágio, a cidade dos ciclos, enfatiza a gestão da demanda de água e o ciclo da água, assim como de outras substâncias, em resposta às limitações do abastecimento de água e assimilação da poluição. Por fim, como último estágio, tem-se a cidade sensível à água, no qual tem-se, adicionalmente, o foco na adaptação, infraestrutura multifuncional e design urbano, reforçando a sensibilidade das águas às alterações climáticas.

Figura 5 - Estrutura de transições relacionadas à gestão de água urbana.

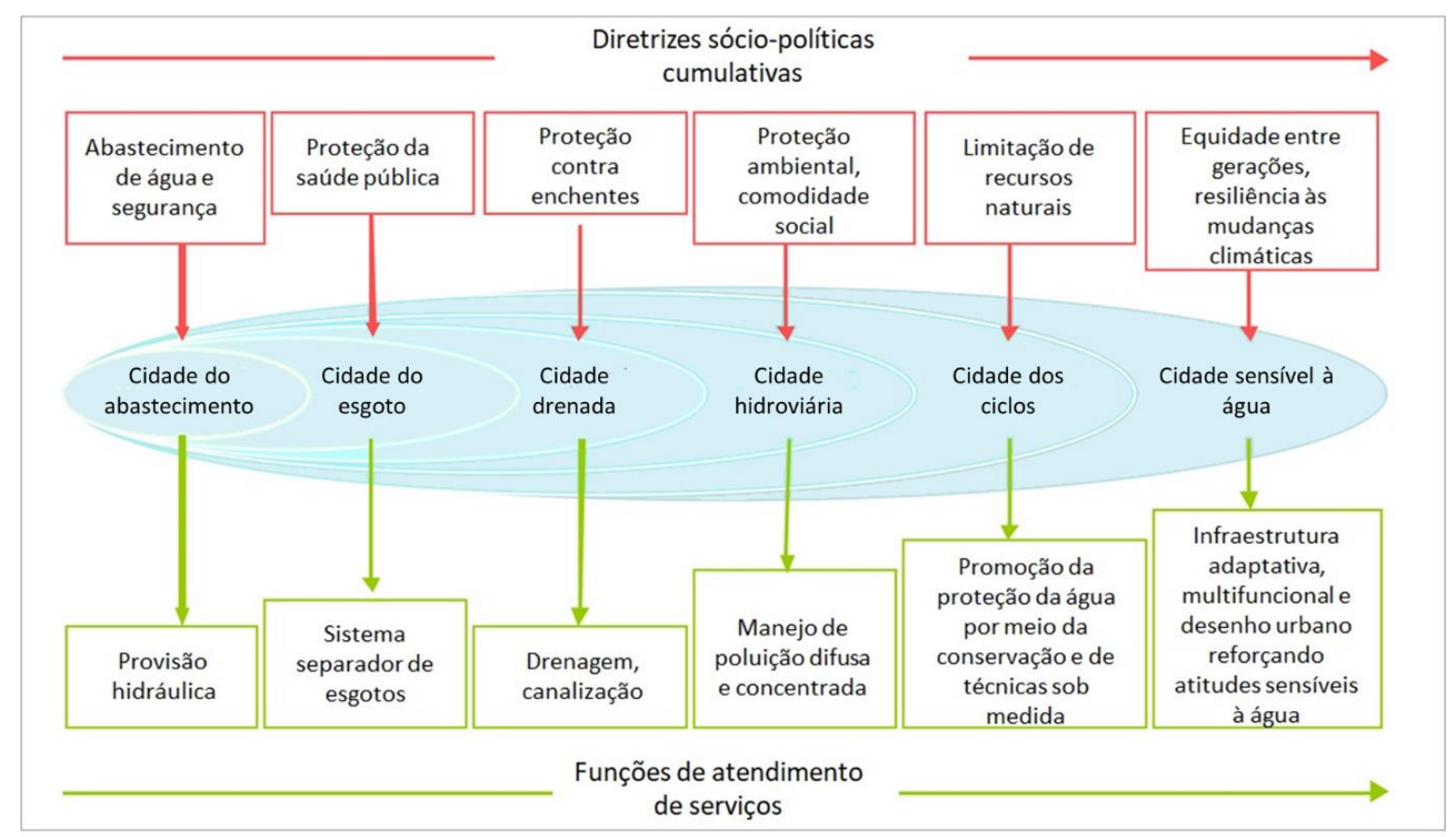

Fonte: Modificado de Brown et al. (2009). 
Research, Society and Development, v. 9, n. 11, e1239119616, 2020

(CC BY 4.0) | ISSN 2525-3409 | DOI: http://dx.doi.org/10.33448/rsd-v9i11.9616

Destaca-se que as transições desses estágios são sustentadas por impulsos sóciopolíticos cumulativos e, em cada estágio, novas funções de prestação de serviços são adicionadas (Brown et al., 2009). Entretanto, de acordo com esses autores, ainda não existiam “cidades sensíveis à água" no mundo, apesar desse conceito atrair cada vez mais a atenção de cientistas e profissionais.

Neste contexto, Hoekstra et al. (2018) destacaram que a maioria das cidades do mundo ainda está buscando resolver os problemas associados à falta de água, poluição e vulnerabilidade à inundações, utilizando soluções "end-of-pipe", como maiores tubulações transportando água a maiores distâncias, tratamento de esgoto e construção de diques.

Dessa forma, visando uma transição bem-sucedida na direção de cidades sustentáveis, resilientes e econômicas, McClymont et al. (2020) indicam uma atenção crescente quanto a integração mais eficaz de soluções baseadas na natureza, como o SUDS, associado à outros componentes urbanos, tais como telhados verdes, tanques de bio-retenção, valas vegetadas e pavimentos permeáveis. Entretanto, esses autores salientam que a promoção da resiliência urbana é um problema multidisciplinar e multiobjetivo, não existindo uma solução única para todas as situações.

\section{Considerações Finais}

O desenvolvimento urbano, ao modificar os processos de drenagem natural pela incorporação de superfícies impermeáveis, afeta o ciclo hidrológico natural da bacia hidrográfica, aumentando o risco de inundações, a possibilidade de poluição dos corpos hídricos pelo carreamento de substâncias e disseminação de doenças de veiculação hídrica.

Dessa forma, este trabalho buscou analisar a evolução espaço-temporal dos artigos publicados e indexados no banco de dados Web of Science acerca da temática drenagem urbana e saneamento. Notou-se o crescimento do número de artigos publicados a partir de 2017, sendo que o Brasil corresponde ao país com maior número de publicações. De modo geral, tal fato pode ser associado ao planejamento urbano inadequado de grande parte das cidades brasileiras.

Com relação às áreas do conhecimento, a diversidade de campos, como Recursos hídricos, Engenharia, Ciências ambientais e ecologia, Tecnologia, Geografia, Saúde pública e Estudos urbanos, reflete a multidisciplinaridade envolvendo a drenagem urbana e o saneamento, promovendo a ideia do planejamento integrado.

A frequência observada quanto as palavras-chave "drenagem urbana" e "saneamento" 
pode ser relacionada ao emprego dessas na pesquisa realizada no banco de dados. Já as palavras-chave "sustentabilidade", "gestão", "sistemas", "saneamento", "água" e "cidades" podem ser vinculadas à busca de uma abordagem integrada para a gestão de sistemas de água urbanos, que, dentre outros aspectos, deve considerar todos os requisitos relacionados à água, tanto antrópicos como ecológicos, e buscar a sustentabilidade equilibrando as necessidades ambientais, sociais e econômicas.

A "poluição" está frequentemente associada aos transbordamentos dos sistemas de esgoto e ao escoamento superficial, podendo resultar na colmatação de estruturas de infiltração, eutrofização e toxicidade de corpos hídricos, risco para a balneabilidade, comprometimento de águas utilizadas no abastecimento e disseminação de doenças, tais como febre amarela, dengue, malária, esquistossomose, leptospirose, cólera e hepatite A.

Por fim, destaca-se que o artigo com maior média de citações no período analisado apresenta os diferentes focos abordados na literatura quanto à "segurança hídrica" e aos estágios associados à evolução e abordagens diversas referentes a esse tema.

Apesar da compreensão da importância de uma gestão hídrica integrada para a construção de cidades sustentáveis, a multidisciplinaridade e os aspectos políticos e econômicos necessários à solução dos problemas envolvendo as drenagens urbanas exigem ainda novas pesquisas por soluções que atendam diferentes perspectivas.

\section{Referências}

Ahiablame, L. M., Engel, B. A., \& Chaubey, I. (2012). Effectiveness of Low Impact Development Practices: Literature Review and Suggestions for Future Research. Water Air Soil Pollut., 223, $4253-4273$.

Almakki, A., Jumas-Bilak, E., Marchandin, H., \& Licznar-Fajardo, P. (2019). Antibiotic resistance in urban runoff. Science of the Total Environment, 667, 64 - 76.

Almeida, B. R., \& Castro, M. B. (2018). Indicadores sócio espaciais e aspectos climáticos no processo saúde-doença. RAEGA, 45, 200 - 213.

Aguiar, M. F., Cecconello, S. T., \& Centeno, L. N. (2019). Basic sanitation versus water vehiculation diseases in the municipality of Pelotas/RS. Holos, 35(3), e7940. 
Baptista, M. B., \& Coelho, M. M. L. P. (2016). Fundamentos de engenharia hidráulica. 4. ed. Belo Horizonte: Editora UFMG, 477.

Baptista, M.; Nascimento, N., \& Barraud, S. (2011). Técnicas compensatórias em drenagem urbana. (2a ed.), Porto Alegre: ABRH, 318 p.

Behera, P. K., Adams, B. J., \& Li, J. Y. (2006). Runoff Quality Analysis of Urban Catchments with Analytical Probabilistic Models. Journal of Water Resources Planning and Management, 132(1), $4-14$.

Blumensaat, F., Leitão, J. P., Ort, C., Rieckermann, J., Scheidegger, A., Vanrolleghem, P. A. \& Villez, K. (2019). How Urban Storm- and Wastewater Management Prepares for Emerging Opportunities and Threats: Digital Transformation, Ubiquitous Sensing, New Data Sources, and Beyond - A Horizon Scan. Environ. Sci. Technol., 53, 8488 - 8498.

Brasil. (1995). Manual de leptospirose. Ministério da Saúde, Brasília, 98.

Brasil. (2004). Doenças infecciosas e parasitárias: guia de bolso. Ministério da Saúde, Secretaria de Vigilância em Saúde, Departamento de Vigilância Epidemiológica. (4a. ed.), ampl. Brasília: Ministério da Saúde, 332 p.

Brasil. (2010a). Manual integrado de Vigilância Epidemiológica da Cólera. Ministério da Saúde, Secretaria de Vigilância em Saúde. Departamento de Vigilância Epidemiológica. 2a. ed. rev. Brasília: Ministério da Saúde, 170.

Brasil. (2010b). Manual integrado de vigilância e controle da febre tifoide. Ministério da Saúde, Secretaria de Vigilância em Saúde, Departamento de Vigilância Epidemiológica. Brasília: Ministério da Saúde, 92.

Brasil. (2014). Vigilância da Esquistossomose mansoni: diretrizes técnicas. Ministério da Saúde, Secretaria de Vigilância em Saúde, Departamento de Vigilância das Doenças Transmissíveis. (4a ed.), Brasília: Ministério da Saúde, 144. 
Brown, R. R., Keath, N., \& Wong, T. H. F. (2009). Urban water management in cities: historical, current and future regimes. Water Science \& Technology, 59(5), 847 - 855.

Butler, D., \& Davies, J.W. (2004). Urban Drainage. (2a ed.), Londres: Taylor and Francis eLibrary, $543 \mathrm{p}$.

Butler, D., \& Parkinson, J. (1997). Towards sustainable urban drainage. Water Science and Technology, 35(9), $53-63$.

CENTAUR. (2016). CENTAUR: Cost Effective Neural Technique for Alleviation of Urban flood Risk. D4.1 Communication Plan. Lead Partner: USFD, 13.

Cunha, M. C. B., \& Cannan, B. (2015). Percepção ambiental de moradores do bairro Nova Parnamirim em Parnamirim/RN sobre saneamento básico. Holos, 31(1), 133 - 143.

Davis, M. L., \& Masten, S. J. (2016). Princípios de Engenharia Ambiental. (3a ed.), Porto Alegre: AMGH, 854.

Dong, X., Guo, H., \& Zeng, S. (2017). Enhancing future resilience in urban drainage system: Green versus grey infrastructure. Water Research, 124, $280 \mathrm{e} 289$.

Elliott, A. H., \& Trowsdale, S. A. (2007). A review of models for low impact urban stormwater drainage. Environmental Modelling \& Software, 22, 394e405.

Ferreira, G. A., Assis, G. H. R., Cordeiro, J., Bernardes, C. D., Lage, M. A., Cordeiro, J. L. (2019). A presença de arsênio em atividades minerárias: uma análise cienciométrica. Research, Society and Development, 8(9), e22891242.

Freitas, C. M., \& Ximenes, E. F. (2012). Enchentes e saúde pública - uma questão na literatura científica recente das causas, consequências e respostas para prevenção e mitigação. Ciência \& Saúde Coletiva, 17(6), 1601 - 1615.

Gasperi, J., Sebastian, C., Ruban, V., Delamain, M., Percot, S., Wiest, L., Mirande, C., Caupos, E., Demare, D., Diallo Kessoo, M., Saad, M., Schwartz, J. J., Dubois, P.; Fratta, C., 
Wolff, H., Moilleron, R., Chebbo, G., Cren, C., Millet, M., Barraud, S., \& Gromaire, M. C. (2014). Micropollutants in urban stormwater: occurrence, concentrations and atmospheric contributions for a wide range of contaminants in three French catchments. Environmental Science and Pollution Research, 21(8), 5267 - 5281.

Gimenez-Maranges, M., Pappalardo, V., Rosa, D., Breuste, J. \& Hof, A. (2020). The transition to adaptive storm-water management: Learning from existing experiences in Italy and Southern France. Sustainable Cities and Society, 55, 102061.

Gonçalves, M. L. R., Kleidorfer, M., \& Rauch, W. (2017). Case study on the use of a combined system as an intermediate solution in Brazil: cost estimate. Water and Environment Journal, $31,478-485$.

Guimarães, J. C. S., Cordeiro, J., Vitorino, D. C. F. R. (2018). Utilização do lodo de esgoto na agricultura: uma análise cienciométrica. Research, Society and Development, 7(9), 01-31, e479391.

Hillmann, M., \& Brierley, G. (2005). A critical review of catchment-scale stream rehabilitation programmes. Journal of Physical Geography, 29(1), 50 - 70.

Hoekstra, A. Y., Buurman, J., \& Van Ginkel, K. C. H. (2018). Urban water security: A review. Environ. Res. Lett., 13, 053002.

Huang, D., Bader, H., Scheidegger, R., Schertenleib, R., \& Gujer, W. (2007). Confronting limitations: New solutions required for urban water management in Kunming City. Journal of Environmental Management, 84, 49 - 61.

Lee, J. H., Bang, K. W., Ketchum, L. H., Choe, J. S., \& Yu, M. J. (2002). First flush analysis of urban storm runoff. The Science of the Total Environment, 293, 163 - 175.

Lee, S., Suits, M., Wituszynski, D., Winstonb, R., Martin, J., \& Lee, J. (2020). Residential urban stormwater runoff: A comprehensive profile of microbiome and antibiotic resistance. Science of the Total Environment, 723, 138033. 
Lima, A. S. C., Scalize, P. S., Arruda, P. N., \& Baumann, L. R. F. (2017). Satisfação e percepção dos usuários dos sistemas de saneamento de municípios goianos operados pelas prefeituras. Eng Sanit. Ambient., 22(3), 415 - 428.

Machado, A. S., Borja, P. C., \& Moraes, L. R. S. (2013). Desafios e oportunidades para implantação de uma das propostas do PEMAPES: o sistema combinado. Gesta, 1(2), 234 250.

Macias-Chapula, C. A. (1998). O papel da informetria e da cienciometria e sua perspectiva nacional e internacional. Ciência da Informação, 27(2), 134 - 140.

McClymont, K., Cunha, D. G. F., Maidment, C., Ashagre, B., Vasconcelos, A. F., Macedo, M. B., Santos, M. F. N., Gomes Júnior, M. N., Mendiondo, E. M., Barbassa, A. P., Rajendran, L., \& Imani, M. (2020). Towards urban resilience through Sustainable Drainage Systems: A multi-objective optimisation problem. Journal of Environmental Management, 275, 111173.

Miguez, M. G.; Gregorio. L. T. \& Veról, A. P. (2018). Gestão de riscos e desastres hidrológicos. $1^{\mathrm{a}}$ ed. Rio de Janeiro: Elsevier, 340 p.

Mitchell, V. G. (2004). Integrated Urban Water Management: A review of current Australian practice. Australian Water Conservation and Reuse Research Program, CSIRO, 58 p.

Mitchell, V. G. (2006). Applying Integrated Urban Water Management Concepts: A Review of Australian Experience. Environmental Management, 37(5), 589 - 605.

Morihama, A. C., Amaro, C., Tominaga, E. N., Yazaki, L. F., Pereira, M. C., Porto, M. F., Mukai, P., \& Lucci, R. M. (2012). Integrated solutions for urban runoff pollution control in Brazilian metropolitan regions. Water Science \& Technology, 66(4), 704 - 711.

Mugume, S. N., Gomez, D. E., Fu, G., Farmani, R., \& Butler, D. (2015). A global analysis approach for investigating structural resilience in urban drainage systems. Water Research, $81,15-26$. 
Nascimento, N. O., Ellis, J. B., Baptista, M. B., \& Deutsch, J. -C. (1999). Using detention basins: operational experience and lessons. Urban Water, 1, 113 - 124.

Nascimento, S. M. M. G., \& Gomes, J. M. A. (2018). Planejamento e orçamento municipal de Teresina para o crescimento econômico e meio ambiente no período de 2014 a 2016. Revista Brasileira de Gestão Urbana, 10(3), 695 - 707.

Obraczka, M., D'alcantara, W. B., \& Lima, L. M. (2017). Management of water resources from the perspective of urban drainage planning and land use: the case of the basin of Trapiche River, in Itaguaí. Sistemas \& Gestão, 12, 215 - 220.

Rego, R. F., Lima, V. C., Lima, A. C., Barreto, M. L., Prado, M. S., \& Strina, A. (2013). Environmental indicators of intra-urban hetererogeneity. Cad. Saúde Pública, 29(6), 1173 1185 .

Resende, R. G., Ferreira, S., \& Fernandes, L. F. R. (2018). O saneamento rural no contexto brasileiro. Revista Agrogeoambiental, 10(1).

Richardson, C. P., \& Tripp, G. A. (2006). Investigation of Boundary Shear Stress and Pollutant Detachment from Impervious Surface during Simulated Urban Storm Runoff. Journal of Environmental Engineering, 132(1), 85 - 92.

Riechel, A., Matzinger, A., Pallasch, M., Joswig, K., Pawlowsky-Reusing, E., Hinkelmann, R. \& Rouault, P. (2020). Sustainable urban drainage systems in established city developments: Modelling the potential for CSO reduction and river impact mitigation. Journal of Environmental Management, 274, 111207.

Riechel, M., Matzinger, A., Pawlowsky-Reusing, E., Sonnenberg, H., Uldack, M.; Heinzmann, B., Caradot, N., Von Seggern, D., \& Rouault, P. (2016). Impacts of combined sewer overflows on a large urban river e Understanding the effect of different management strategies. Water Research, 105, $64-273$. 
Rodrigues, J. S., Cordeiro, J., Calazans, G. M., Cordeiro, J. L., Guimarães, J. C. S. (2018). Presença de fármacos e hormônios na água: uma análise cienciométrica. Research, Society and Development, 7(6), 01-22, e776185.

Sansalone, J. J., \& Cristina, C. M. (2004). First Flush Concepts for Suspended and Dissolved Solids in Small Impervious Watersheds. Journal of Environmental Engineering, 130(11), $1301-1314$.

Santos, D. C. \& Benetti, A. (2014). Application of the urban water use model for urban water use management purposes. Water Sci Technol., 70(3), 407 - 413.

Santos, J. T., Guimarães, J. C. S., Franco, A., Cordeiro, J., Alvarenga, C. A., Santos, C. I. F., Therezo, P. (2018). Resíduos sólidos orgânicos: uma análise cienciométrica acerca da utilização da compostagem para a geração de adubo. Research, Society and Development, 7(12), 01-23, e14712498.

Silva, T. F. G., Vincon-Leite, B., Lemaire, B. J., Petrucci, G., Giani, A., Figueredo, C. C., \& Nascimento, N. D. (2019). Impact of Urban Stormwater Runoff on Cyanobacteria Dynamics in A Tropical Urban Lake. Water, 11(5), 946.

Silveira, A. L. (2002). Problems of modern urban drainage in developing countries. Water Sci Technol, 45(7), $31-40$.

Sistema Nacional de Informações de Saneamento (SNIS). (2019). $3^{o}$ Diagnóstico de drenagem e manejo de águas pluviais. Brasília: Sistema Nacional de Saneamento/ Ministério de Desenvolvimento Regional. 195 p.

Sistema Nacional de Informações de Saneamento (SNIS). (2020). Diagnóstico anual de Águas Pluviais. Recuperado de http://www.snis.gov.br/diagnostico-anual-aguas-pluviais.

Soares, S. R., Parkinson, J., \& Bernardes, R. S. (2005). Analysis of scenarios for wastewater and urban drainage systems in Brazil based on an integrated modeling approach. Water Sci Technol., 52(9), $53-60$. 
Souza, C. M. N., \& Freitas, C. M. (2008). O saneamento na ótica de profissionais de saneamento-saúde-ambiente: promoção da saúde ou prevenção de doenças? Eng. Sanit. Ambient., 13(1), 46 - 53.

Tasca, F. A., Pompêo, C. A., \& Finotti, A. R. (2018). Evolução da gestão da drenagem urbana na bacia hidrográfica do Rio Itajaí Açu. Rev. Gest. Ambient. Sustentabilidade, 7(2), 264 - 283.

Tucci, C. E. M. (2005). Gestão de Águas Pluviais Urbanas. Ministério das Cidades. Global Water Partnership, Wolrd Bank, Unesco, 270 p.

Vanti, N. A. P. (2002). Da bibliometria à webometria: uma exploração conceitual dos mecanismos utilizados para medir o registro da informação e a difusão do conhecimento. Ciência da Informação, 31(2), 152-162.

\section{Porcentagem de contribuição de cada autor no manuscrito}

Juni Cordeiro $-25 \%$

Fábio Henrique Silva $-25 \%$

Felipe Angelo Neves Campera - 25\%

Flávio Costa $-25 \%$ 